\title{
A UNIVERSALIZAÇÃO DOS DIREITOS HUMANOS, O DIREITO À SAÚDE E A SAÚDE PÚBLICA
}

\author{
THE UNIVERSALIZATION OF HUMAN RIGHTS, THE RIGHT TO HEALTH AND THE PUBLIC
}

HEALTH

Flávio Roberto Batista*

\begin{abstract}
Resumo:
$\mathrm{O}$ artigo trata do tema da universalização dos direitos humanos à luz de uma leitura do direito à saúde feita a partir de sua coletivização, representada pelo fenômeno da saúde pública. Depois de considerações teóricas sobre todos os temas envolvidos, o desenvolvimento culmina no exame de dois casos práticos: o infanticídio indígena e a recusa de tratamento médico por religiosos.
\end{abstract}

Palavras-chave: Direitos humanos. Direito à saúde. Saúde pública.

\begin{abstract}
:
The paper deals with the theme of the universalization of human rights from a right to health's view, since its collectivization, represented by the public health phenomenon. After theoretical considerations of all the issues involved, this paper examines two case studies: indigenous infanticide and the refusal of medical treatment by religious people.
\end{abstract}

Keywords: Human rights. Right to health. Public health.

\section{Introdução}

O presente estudo tem por finalidade investigar o fenômeno da universalização dos direitos humanos ${ }^{1}$ por meio do método indutivo, através da relação entre o direito à saúde e o conceito de saúde pública.

O tema do direito à saúde é um dos maiores problemas enfrentados pela doutrina dos direitos humanos, particularmente para os estudiosos dos direitos sociais. Sua importância decorre principalmente de dois fatores.

$\mathrm{O}$ direito à saúde talvez seja o direito social que está mais diretamente ligado à dignidade da pessoa humana. É uma noção até mesmo instintiva a de que uma vida humana não é dignamente vivida senão com saúde. Além disso, segundo certa corrente

Professor Doutor do Departamento de Direito do Trabalho e da Seguridade Social da Faculdade de Direito da Universidade de São Paulo. E-mail para contato: flavio@usp.br.

1 Não serão levadas em conta as eventuais diferenças terminológicas verificadas na doutrina, envolvendo as expressões "direitos fundamentais", "direitos humanos", entre outras, sendo todas elas aqui utilizadas como sinônimas. 
doutrinária, ${ }^{2}$ a dignidade da pessoa humana foi positivada pela Constituição Federal como sobreprincípio a iluminar todo o sistema jurídico, e particularmente os direitos sociais. Paralelamente a isso, o direito à saúde é ainda parcamente garantido, muito em função do mito de seu alto custo de implementação.

O segundo ponto que chama atenção é a grande controvérsia em torno da definição do que seja saúde, e que interfere diretamente no direito à saúde à medida que é impossível garantir um direito sem que se conheça plenamente seu objeto.

Por fim, também traz grandes consequências para a aplicação do direito à saúde a investigação de sua natureza, isto é, por um lado, sua identificação como direito social entre os direitos fundamentais; e, por outro lado, a revelação da espécie de direito a que pertence: individual homogêneo, coletivo, ou difuso.

Assim sendo, a primeira parte do estudo consistirá em um estudo detalhado do direito à saúde, compreendendo a descrição de seu objeto e de sua natureza.

A tarefa seguinte empreende uma mudança de plano, do singular para o universal. Com base nas conclusões obtidas a respeito da natureza do direito à saúde, será feito um apanhado do conceito e da evolução histórica da saúde pública, analisando a relação entre esta ideia e o direito à saúde. Será importante nesse passo a discussão de alguns casos concretos de conflito entre medidas de saúde pública e a efetivação do direito à saúde.

Estabelecida a relação em comento, a parte principal do estudo se apoiará nela para discutir a questão da universalização dos direitos humanos, investigando as diversas acepções dessa expressão na doutrina e, com base nas exposições dos casos concretos, analisará a possibilidade e a conveniência da universalização dos direitos humanos. Eis o trajeto a ser percorrido.

2. $\mathrm{O}$ direito à saúde

2.1. O conceito de saúde

O direito à saúde é garantido pela Constituição Federal do Brasil de 1988 CF, por meio de seu art. 196:

A saúde é direito de todos e dever do Estado, garantido mediante políticas sociais e econômicas que visem à redução do risco de doença e outros agravos e ao acesso universal.

O texto, como uma leitura superficial revela, não define o que entende por saúde, tratando apenas de sua garantia. Em outras palavras, define os meios, mas não

2 Cf. BARROSO, Luís Roberto. Interpretação e aplicação da constituição. 6. ed. São Paulo: Saraiva, 2004. p. 330 e ss. 
define os fins. Cumpre, portanto, tecer algumas considerações sobre o conceito de saúde e sua evolução, anotando que, para tanto, serão necessários alguns subsídios tomados das ciências médicas.

É absolutamente impertinente para os nossos propósitos uma descrição detalhada de toda a evolução histórica do conceito de saúde. Entretanto, importa que se deixe bem marcada a divisão dessa evolução em três fases. A primeira delas consiste no chamado paradigma saúde-doença, que propugna uma concepção negativa de saúde, entendendo-a como ausência de doenças.

O paradigma saúde-doença dominou a ciência médica por muito tempo, até mesmo por seu caráter fortemente intuitivo, além de ser "conceitualmente confortável e metodologicamente viável ". ${ }^{3}$ A impossibilidade de sua adoção, entretanto, já foi cabalmente demonstrada. A esse respeito, a opinião de Almeida Filho, médico epidemiologista, é lapidar:

Não há qualquer base lógica para uma definição negativa de Saúde, tanto no nível individual quanto no coletivo, mesmo em suas versões aparentemente mais avançadas e completas. (...) Em uma perspectiva rigorosamente clínica, portanto, a Saúde não é o oposto lógico da doença e, por isso, não poderá de modo algum ser definida como 'ausência de doença'. ${ }^{4}$

A segunda fase da evolução tem por marco inicial a definição de saúde firmada pela Organização Mundial de Saúde - OMS, em 1946:

Saúde é o estado de completo bem-estar físico, mental e social, e não meramente a ausência de doença ou incapacidade. $^{5}$

Este conceito é, sem dúvida alguma, bastante abrangente, tendo sido esculpido em meados da década de 40, imediatamente após a Segunda Guerra Mundial, no contexto das declarações internacionais de direitos humanos e do início da melhor fase do welfare state. O valor dessa definição, nesse bojo, é inquestionável, sendo reconhecido até mesmo por seus críticos, que a consideraram "avançada para a época em que foi realizada". ${ }^{6}$

\footnotetext{
3 ALMEIDA FILHO, Naomar de. O conceito de saúde e a vigilância sanitária. Brasília: ANVISA, 2000. p. 6.

4 ALMEIDA FILHO, Naomar de. O conceito de saúde: ponto-cego da epidemiologia? Revista Brasileira de Epidemiologia, v. 3, n. 1, São Paulo, abr./dez. 2000. p. 7-8.

5 Traduzido livremente de WORLD HEALTH ORGANIZATION. Advanced health technologies and medical ethics - A WHO perspective. Disponível em: <http://www.who.int/ethics/en/S_Groth_Advanced_Health_ Technologies.pdf>. p. 9. Acesso em: 1 maio 2012.

6 SEGRE, Marco; FERRAZ, Flávio Carvalho. O conceito de saúde. Revista de Saúde Pública, São Paulo, v. 31, n. $5,1997$. p. 539 .
} 
O tempo, entretanto, foi-lhe implacável. A prática demonstrou também sua inviabilidade, a exemplo do que ocorreu com o paradigma anterior, e o conceito da OMS passou a ser considerado "irreal, ultrapassado e unilateral". ' Irreal, pois a perfeição é uma utopia; ultrapassado, por fazer a distinção entre físico, mental e social, já afastada pela moderna ciência médica; e unilateral, na medida em que elimina toda a subjetividade que impregna a noção de bem-estar. Outros críticos foram menos piedosos e extremamente sarcásticos. Confira-se, a respeito, o já citado Almeida Filho:

Em 1946, talvez buscando uma terapêutica para o zeitgeist depressivo do pós-guerra, a Organização Mundial de Saúde reinventou o Nirvana e chamou-o de 'saúde' (destaque do original). ${ }^{8}$

As críticas à definição de saúde da OMS culminaram com a terceira fase. Atualmente, vige a ideia de que a saúde é necessariamente dinâmica. A teoria do conceito de saúde não está unificada e sistematizada, mas, de modo geral, pode-se dizer que a saúde, nessa terceira e última fase, é, por um lado, um processo, e, por outro lado, o objetivo desse mesmo processo. Como processo, logicamente não estático, a saúde carregaria implicitamente a ideia de risco. Ilustrativamente, algumas opiniões a respeito:

A saúde é, pois, um processo que se constrói. ${ }^{9}$

O completo bem-estar do ser humano é um processo, ou seja, a saúde é uma busca contínua pelo 'equilíbrio entre influências ambientais, modos de vida e os vários componentes'. ${ }^{10}$

A saúde é um estado de razoável harmonia entre o sujeito e sua própria realidade. ${ }^{11}$

SEGRE, Marco; FERRAZ, Flávio Carvalho. O conceito de saúde. Revista de Saúde Pública, São Paulo, v. 31, n. 5, 1997. p. 539.

8 ALMEIDA FILHO, Naomar de. O conceito de saúde: ponto-cego da epidemiologia? Revista Brasileira de Epidemiologia, São Paulo, v. 3, n. 1, abr./dez. 2000. p. 5.

9 SCHWARTZ, Germano. Direito à saúde: Abordagem sistêmica, risco e democracia. Revista de Direito Sanitário, São Paulo, v. 2, n. 1, 2001. p. 31. Este autor adota a teoria de Niklas Luhmann acerca dos sistemas sociais para sustentar que a saúde é um sistema cuja dinâmica consiste numa decisão que resultará numa ação, e que, portanto, contém graus de risco.

10 ROCHA, Júlio César de Sá. Direito da saúde: direito sanitário na perspectiva dos interesses difusos e coletivos. São Paulo: LTr, 1999. p. 43.

11 SEGRE, Marco; FERRAZ, Flávio Carvalho. O conceito de saúde. Revista de Saúde Pública, São Paulo, v. 31, n. 5, 1997. p. 542. 
Esta é a situação em que se encontra a doutrina nos dias atuais. Por outro lado, é razoável supor que, existindo regulação positiva da saúde no direito brasileiro, deve existir um conceito normativo de saúde em nosso ordenamento.

A CF fornece subsídios para tanto, com a redação de seu art. 196, transcrito acima. A menção a "políticas" e à "redução do risco de doença e de outros agravos" deixa clara a pressuposição de uma visão processual da saúde, trazendo implícita a ideia de risco. A despeito disso, não falta quem identifique na CF uma consagração do conceito da OMS, com base em sua ampla garantia teórica de bem-estar em diversos campos:

Por tudo que mencionamos, o conceito jurídico de saúde somente pode ser compreendido numa análise sistemática, extraindo a noção de saúde como completo bem-estar, acompanhando a ideia-força traçada pela Organização Mundial de Saúde. ${ }^{12}$

A Lei n. 8.080/90, Lei Orgânica da Saúde - LOS, parece corroborar esse entendimento ao enunciar, em seu art. $3^{\circ}$ :

\begin{abstract}
Art. $3^{\circ}$. A saúde tem como fatores determinantes e condicionantes, entre outros, a alimentação, a moradia, o saneamento básico, o meio ambiente, o trabalho, a renda, a educação, o transporte, o lazer e o acesso aos bens e serviços essenciais; os níveis de saúde da população expressam a organização social e econômica do País.
\end{abstract}

Parágrafo único. Dizem respeito também à saúde as ações que, por força do disposto no artigo anterior, se destinam a garantir às pessoas e à coletividade condições de bem-estar físico, mental e social.

A LOS, entretanto, não pode contrariar uma disposição constitucional, mesmo que amparada por uma distorcida interpretação sistemática. As garantias sociais da CF encontram-se vinculadas a outras esferas que não a da saúde, a qual deve ter por cerne, nos termos do art. 196, as ideias de processo sistêmico e risco.

Temos, portanto, que, hoje, tanto na doutrina quanto em nível normativo, a saúde é um processo sistêmico, informado pela ideia de risco, cuja dinâmica consiste na tomada de decisões que resultarão em ações - ou políticas - em matéria de saúde, tendo sempre por objetivo a elevação do grau de saúde da população por meio da diminuição do risco de doenças e outros agravos.

12 ROCHA, Júlio César de Sá. Direito da saúde: direito sanitário na perspectiva dos interesses difusos e coletivos. São Paulo: LTr, 1999. p. 45. 


\title{
2.2. A natureza do direito à saúde
}

A discussão da natureza jurídica do direito à saúde pode ser feita em dois planos.

Em primeiro lugar, o direito à saúde é um direito fundamental. Essa asserção, que por si só ensejaria a necessidade de um estudo aprofundado, será adotada como premissa, bastando, para sua justificativa, o fato de ser amparada pelo direito positivo, conforme anotou Ingo Sarlet:

Nossa Constituição se refere aos 'Direitos e Garantias Fundamentais', consignando-se aqui o fato de que este termo - de cunho genérico - abrange todas as demais espécies ou categorias de direitos fundamentais, nomeadamente os direitos e deveres individuais e coletivos (Capítulo I), os direitos sociais (Capítulo II), a nacionalidade (Capítulo III), os direitos políticos (Capítulo IV) e o regramento dos partidos políticos (Capítulo V). ${ }^{13}$

Dentre os direitos fundamentais, o direito à saúde, por força do art. $6^{\circ}$ da $\mathrm{CF}$, é um direito social. ${ }^{14}$ Esta caracterização, embora aparentemente tranquila, demanda algumas precisões para evitar equívocos teóricos muito comuns. É que, embora a CF enumere os direitos sociais, não há uma definição positiva destes direitos, ficando o trabalho para a doutrina dos direitos fundamentais. E, com relação a esse assunto, a concepção mais difundida é a teoria das gerações de direitos de Norberto Bobbio. Júlio César de Sá Rocha faz uma exposição sucinta da teoria:

\begin{abstract}
A teoria da geração de direitos elaborada por Norberto Bobbio propõe a existência de fases históricas para surgimento de determinados direitos. Em cada momento histórico aparecem diferentes tipos de direitos: direitos de primeira, segunda, terceira e quarta geração. (...). Em seguida, surgem os de segunda geração, os direitos sociais ou coletivos, v.g., direito à saúde, direito ao trabalho, resultado das mudanças estruturais na sociedade e do Estado pós-Revolução Industrial (séc. XIX). Os direitos sociais 'exigem o dever do Estado na criação de pressupostos materiais, indispensáveis ao exercício efetivo destes direitos'. ${ }^{15}$
\end{abstract}

\footnotetext{
13 SARLET, Ingo Wolfgang. A eficácia dos direitos fundamentais. 2. ed. Porto Alegre: Livraria do Advogado, 2001. p. 32. Cumpre anotar que, dentre os referidos pelo autor, o direito à saúde encontra-se no Capítulo II.

14 "Art. 6". São direitos sociais a educação, a saúde, o trabalho, a moradia, o lazer, a segurança, a previdência social, a proteção à maternidade e à infância, a assistência aos desamparados, na forma desta Constituição".

15 ROCHA, Júlio César de Sá. Direito da saúde: direito sanitário na perspectiva dos interesses difusos e coletivos. São Paulo: LTr, 1999. p. 45.
} 
A teoria das gerações de direitos não deve ser adotada como parâmetro para a definição dos direitos sociais. Em primeiro lugar, porque a teoria, destinada a ser uma explicação descritiva histórica da evolução dos direitos fundamentais, não tem validade histórica. Isso porque, embora no âmbito do direito constitucional interno dos países a evolução dos direitos tenha obedecido a esta ordem, no plano internacional a cronologia foi diversa.

Além disso, o uso do termo gerações de direitos é extremamente perigoso. A teoria dos direitos humanos deve ter por finalidade promover sua integração e realização concomitante, de modo a atingir de forma mais plena a dignidade da pessoa humana. A palavra gerações serve ao fim completamente oposto a esse, ao sugerir a ideia de sucessão entre as diversas gerações de direitos, e não de sua integração.

Ademais, a divisão dos direitos em diversas gerações permite, sem contradição lógica, e até mesmo estimula a admissão de preconceitos intoleráveis entre os direitos fundamentais. Somente por meio da divisão dos direitos em gerações é possível considerar alguns deles mais fundamentais que os outros, seja em função de serem estabelecidos por normas programáticas, seja em função de terem um alto custo de implementação. Tratam-se de perniciosos mitos. Todos os direitos fundamentais são colocados por normas hierarquicamente idênticas, cláusulas pétreas constitucionais. Além disso, somente a título exemplificativo, a liberdade política, um dos mais representativos direitos "de primeira geração", demanda vultosos gastos com eleições a cada dois anos, de modo que acaba por custar tanto quanto ou até mais que os direitos de "segunda geração".

Por fim, temos que os direitos sociais possuem uma tríplice perspectiva. São direitos de fruição individual, cuja demanda é eminentemente coletiva e em cuja fruição o interesse da sociedade se manifesta de forma difusa. O tema será abordado com mais vagar adiante, pois respeita diretamente à outra dimensão de estudo da natureza do direito à saúde. Por ora, basta, para este reconhecimento, a discussão sempre acalorada sobre a possibilidade de direitos sociais não efetivados darem origem a direitos subjetivos - manifestação da fruição individual - e o fato de ser o direito da seguridade social, de "segunda geração", informado pelo princípio da solidariedade, ideia-vetor dos direitos "de terceira geração". ${ }^{16}$

Fixamos, assim, que não se pode chamar o direito à saúde de direito de “segunda geração". Ele é um direito social, e isso é suficiente, anotando-se que, para os nossos propósitos, os direitos sociais são aqueles previstos no art. $6^{\circ}$ da $\mathrm{CF}$.

16 Uma caracterização completa dessas críticas pode ser encontrada em CORREIA, Marcus Orione Gonçalves. Os direitos sociais enquanto direitos fundamentais. In: CORREIA, Marcus Orione Gonçalves; CORREIA, Érica Paula Barcha (Coord.). Direito previdenciário e constituição: homenagem a Wladimir Novaes Martinez. São Paulo: LTr, 2004. p. 25-28. 
O segundo plano de investigação do direito à saúde consiste em determinar a categoria à qual pertence entre os direitos genericamente referidos como "não individuais". O tratamento da matéria no direito brasileiro é feito pelo Código de Defesa do Consumidor - CDC, no parágrafo único do art. 81. Convém que se faça a transcrição do dispositivo:

Parágrafo único. A defesa coletiva será exercida quando se tratar de:

I - interesses ou direitos difusos, assim entendidos, para efeitos deste código, os transindividuais, de natureza indivisível, de que sejam titulares pessoas indeterminadas e ligadas por circunstâncias de fato;

II - interesses ou direitos coletivos, assim entendidos, para efeitos deste código, os transindividuais, de natureza indivisível de que seja titular grupo, categoria ou classe de pessoas ligadas entre si ou com a parte contrária por uma relação jurídica base;

III - interesses ou direitos individuais homogêneos, assim entendidos os decorrentes de origem comum.

Como direito social que é, o direito à saúde pode ser visto por um triplo viés. $\mathrm{O}$ direito à saúde é, antes de tudo, um direito individual. Sua ligação com o direito à vida, mais individual dos direitos, é inescapável. Além disso, sua garantia constitucional alude ao fato de ser um "direito de todos", fórmula típica de um direito individual homogêneo. Por fim, com relação à classificação do CDC, ele é divisível, razão pela qual sua dimensão de fruição é necessariamente individual homogênea. Em outras palavras, um direito que, apesar de ser de fruição individual, é de titularidade de todos, indistintamente. Sua origem comum é a própria garantia da $\mathrm{CF}$.

Um segundo aspecto do direito à saúde é sua face coletiva. A demanda pela saúde necessariamente adquire esse viés em função de sua municipalização determinada pela LOS, em atenção ao disposto no art. 198, I, da CF. Assim, a garantia da saúde, como responsabilidade do Estado a ser demandada, seja social ou juridicamente, pertence sempre a um grupo de pessoas habitantes da mesma municipalidade.

Por fim, chama atenção o aspecto difuso do direito à saúde. Ele fica evidente em certos caracteres do tratamento normativo desse direito. Primeiramente quando a CF garante seu acesso universal - art. 194, parágrafo único, I. A garantia de um acesso universal, além de atribuir um grande grau de indeterminação à titularidade do direito, torna claro o interesse da sociedade em que o acesso ao direito à saúde seja o mais amplo possível. Esse interesse social não é individualizado, sendo que o benefício decorrente de sua realização é experimentado de forma difusa. 
Depois, fazendo parte da seguridade social, o direito à saúde é necessariamente informado pelo princípio da solidariedade social, implicitamente contido nos arts. 194 e 195 da CF. Esse fato os aproxima, ainda que apenas em uma de suas dimensões, dos direitos fundamentais de solidariedade, os direitos de "terceira geração". Trata-se de direitos cuja titularidade é sempre difusa. A informação do direito à saúde pela mesma ideia-vetor dos direitos de titularidade difusa demonstra que sua dimensão de interesse social também apresenta esta característica.

Fixado o ponto de que o direito à saúde possui três possíveis vieses, cada um dos quais pertencente a uma diferente categoria de direito não individual, podemos passar à segunda parte do estudo, que trata do conceito de saúde pública.

3. A saúde pública

3.1. O conceito de saúde pública

A discussão conceitual da saúde pública não apresenta, historicamente, paralelismo com o conceito de saúde, da mesma forma que seu surgimento como ciência nada tem a ver com o surgimento das ciências da saúde, notadamente a ciência médica. Michel Foucault, em estudo exaustivo e bastante interdisciplinar, faz um apanhado histórico do que ele chama de "medicina social", encontrando seu surgimento em três momentos diferentes, sob três formas diferentes, em três países diferentes. ${ }^{17}$

Segundo o autor, na Alemanha a medicina social surgiu como medicina de Estado, junto a própria ciência do Estado, justamente no lugar em que o Estado, como manifestação de poder, mostrava-se um dos mais fracos em toda a Europa. A medicina de Estado alemã caracterizava-se pela "organização de um saber médico estatal, a normalização da profissão médica, a subordinação dos médicos a uma administração central e, finalmente, a integração de vários médicos em uma organização médica estatal". 18

A medicina de Estado surgiu num contexto de medição da força populacional dos Estados, levada a cabo em função da ideia mercantilista. Esse movimento de medição deu-se generalizadamente em toda a Europa, mas apenas na Alemanha tinha como objetivo a elevação do nível da saúde da população, sendo este o único país a alcançar considerável grau de estatização da medicina.

Foi na França que se verificou a segunda manifestação de medicina social. Ali, a medicina social surgiu no contexto do desenvolvimento das estruturas urbanas, por

\footnotetext{
17 FOUCAULT, Michel. O nascimento da medicina social. In: FOUCAULT, Michel. Microfisica do poder. Rio de Janeiro: Graal, 1999. p. 79-98.

18 Id. Ibid., p. 84.
} 
motivos de diversas ordens, como a necessidade de unificação do poder das cidades e o medo causado por pequenas crises decorrentes da aglomeração urbana mal planejada, causado principalmente pela presença dos cemitérios. A medicina urbana tem como principal objeto, portanto, a eliminação das possíveis contaminações presentes na cidade. Seu método, diferentemente das antigas práticas de exílio adotadas em tempos mais antigos, consistia em análise minuciosa de toda a área urbana, de forma quase militar, com três objetivos: adquirir conhecimento sobre regiões de aglomeração, controlar e implantar a boa circulação de água e ar, e organizar a distribuição dos elementos essenciais ao funcionamento da cidade da forma menos prejudicial à saúde.

A medicina urbana francesa esteve, portanto, muito ligada à noção de higiene pública, ao contrário da medicina de Estado alemã, calcada no potencial produtivo e na elevação do nível de saúde da população. Além disso, Foucault faz a seguinte distinção entre as duas manifestações da medicina social:

Vê-se, assim, como se está bastante longe da medicina de Estado, tal como é definida na Alemanha, pois se trata de uma medicina muito mais próxima das pequenas comunidades, das cidades, dos bairros, como também ainda não é dotada de nenhum instrumento específico de poder. O problema da propriedade privada, princípio sagrado, impede que esta medicina seja dotada de um poder forte. Mas, se ela perde em poder para a Staatsmedizin alemã, ganha certamente em fineza de observação, na cientificidade das observações feitas e das práticas estabelecidas. ${ }^{19}$

Por fim, o terceiro momento de surgimento da medicina social passou-se na Inglaterra. $\mathrm{O}$ vetor dessa manifestação da medicina social era o controle médico dos pobres, como um dos instrumentos para seu controle político. As práticas de medicina social dessa realidade consistiam em estabelecer um cordão sanitário autoritário entre pobres e ricos, como parte da intenção maior de manter a segurança da burguesia, criandose, para isso, a possibilidade do tratamento médico gratuito aos pobres, de forma a evitar epidemias. O pobre era tomado como objeto também na condição de proletário, uma vez que, nesse momento, desenvolviam-se as relações de produção capitalista e era necessária mão de obra em boas condições de saúde para a extração da mais-valia.

Paralelamente aos cuidados médicos dos pobres concedidos como uma forma de controle, criou-se um sistema autoritário de controle médico transindividual, com foco nas medidas preventivas e nas coisas, nos locais, no espaço de maneira geral, a exemplo do que se passou na França. Novamente Foucault, sobre o caso inglês:

19 Id. Ibid., p. 93. 
Essa fórmula de medicina social inglesa foi a que teve futuro, diferentemente da medicina urbana francesa e sobretudo da medicina de Estado. O sistema inglês de Simon e seus sucessores possibilitou, por um lado, ligar três coisas: assistência médica ao pobre, controle de saúde da força de trabalho e esquadrinhamento geral da saúde pública, permitindo às classes mais ricas se protegerem dos perigos reais. ${ }^{20}$

Por conta desse caráter multifacetado, a medicina social inglesa permitia a coexistência de um sistema médico de assistência gratuita aos pobres, um de índole estatal que cuidava de assuntos abrangentes como vacinas e epidemias, e um privado utilizado por quem podia pagá-lo. Nesses sistemas, o poder poderia ser exercido conforme a necessidade, e atingindo somente os setores populacionais necessários. Essa foi, segundo o autor, a forma de medicina social que se perpetuou generalizadamente nos países industrializados após a influência do Plano Beveridge, modificando-se somente, em pequena escala, a forma de articulação dos três sistemas referidos.

Feito esse apanhado histórico, nota-se que suas conclusões correspondem integralmente à noção clássica de saúde pública, que é captada com precisão no texto de Sueli Dallari:

Contudo, atualmente, ${ }^{21}$ a saúde não tem apenas um aspecto individual que respeita apenas a pessoa. Não basta que sejam colocados à disposição dos indivíduos todos os meios para promoção, manutenção ou recuperação da saúde para que o Estado responda satisfatoriamente à obrigação de garantir a saúde do povo. Hoje os Estados são, em sua maioria, forçados por disposição constitucional a proteger a saúde contra todos os perigos. Até mesmo contra a irresponsabilidade de seus próprios cidadãos. A saúde 'pública' tem um caráter coletivo. O Estado contemporâneo controla o comportamento dos indivíduos no intuito de impedir-lhes qualquer ação nociva à saúde de todo o povo. E o faz por meio de leis. ${ }^{22}$

A noção de saúde pública, entretanto, foi atingida pela mesma crise paradigmática que assola o conceito de saúde. Assim, já existe, atualmente, uma tendência doutrinária que visa a superar a ideia de saúde pública com um viés de controle normativo, conforme apresentada nas concepções de Foucault e Sueli Dallari. A crítica é tão profunda

$20 \quad$ Id. Ibid., p. 97.

$21 \quad$ Note-se que o texto foi escrito em 1988.

22 DALLARI, Sueli Gandolfi. Uma nova disciplina: o direito sanitário. Revista de Saúde Pública, São Paulo, n. 22 , v. 4,1988 . p. 330 . 
que passa inclusive por uma modificação no próprio nome do conceito. Trata-se do que está sendo chamado de saúde coletiva.

Não é objeto deste trabalho debater exaustivamente a crise epistemológica da saúde pública e sua substituição gradual pela noção de saúde coletiva. Basta, para nossos propósitos, anotar que o questionamento parece bastante pertinente, e fornecer uma síntese de sua essência, amparada em diversas referências sobre o tema, dividindo a saúde coletiva em um lado científico e um lado prático:

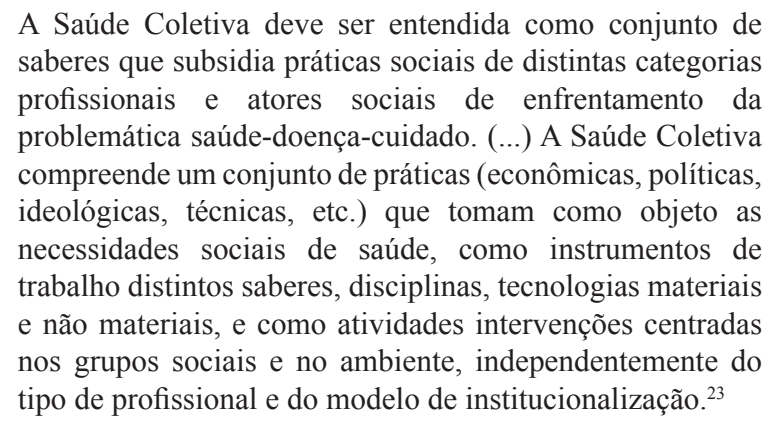

Não é difícil notar, portanto, que, ao menos no que tange à doutrina especializada, isto é, não jurídica, o conceito de saúde coletiva, suplantando o de saúde pública, eliminou sua carga de autoritarismo e de isolamento sanitário de riscos epidêmicos, apresentando como objetivo, em certa medida, o incremento do nível de saúde da população, a exemplo da medicina de Estado alemã, porém de forma extremamente mais sofisticada. Dessa forma, por um lado, a saúde pública deixa de atuar somente sobre os desfavorecidos, reprimindo-os, e passa a atuar sistemicamente na sociedade como um todo, acompanhando a noção sistêmica já apresentada com relação à saúde. Por outro lado, seu objetivo promocional de saúde traz diversos novos problemas, reinserindo a questão do conceito de saúde na problemática da saúde pública.

\subsection{Exame de exemplos concretos}

\subsubsection{As pequenas índias Zuruahã}

Um caso ocorrido no Brasil foi noticiado na grande mídia para o mundo todo. ${ }^{24}$ Trata-se de duas índias recém-nascidas, da tribo Zuruahã, da Amazônia: Sumawani,

23 ALMEIDA FILHO, Naomar de. O conceito de saúde e a vigilância sanitária. Brasília: ANVISA, 2000. p. 10.

24 Paraumatranscriçãodamatériaapresentada,cf.REDEGLOBODETELEVISÃO.Odramadeduasindiazinhas Zuruahã. Disponível em: <http://fantastico.globo.com/Jornalismo/FANT/0,MUL695084-15605,00.html>. Acesso em: 1 maio 2012. 
hermafrodita; e Iganani, com paralisia cerebral. Pelas leis da tribo, amparadas em sua cultura e seu entendimento de mundo, os bebês deveriam ser abandonados na floresta para encontrar a morte, por terem nascido doentes.

A tribo Zuruahã vivia até há cerca de vinte anos isolada de qualquer contato com o homem branco, quando foi encontrada por uma equipe de antropólogos que, inclusive, lhe atribuiu esse nome com base em conversa com os próprios indígenas. A tribo, além disso, nem mesmo é capaz de se comunicar em língua portuguesa, havendo necessidade de um intérprete. Ainda assim, vinte anos de contato com a "civilização" já causaram profundos efeitos. A avó de Sumawani e a mãe e a avó de Iganani, já influenciadas pela cultura eurocêntrica, impediram a morte das crianças, pedindo ajuda a missionários que levaram as famílias a São Paulo para receberem tratamento médico.

A questão que se coloca diante desse caso é: como foi tratado o direito à saúde das pequenas índias? A medida tomada pelos missionários pode ser considerada uma medida de saúde pública?

Os questionamentos exigem que seja revisitada a primeira discussão empreendida, a respeito do conceito de saúde.

Adotado o conceito clássico negativo de saúde, não há que se duvidar que os missionários buscaram garantir o direito à saúde das crianças. É patente que as meninas são portadoras de doenças, cujo tratamento foi-lhes propiciado pelos missionários.

Por outro lado, segundo a noção da OMS, o problema certamente suscitaria aceso debate. É que a atitude dos missionários, caso levada a efeito, atuaria no sentido de eliminar a doença das crianças e de promover seu perfeito bem-estar físico. O mesmo, entretanto, não se pode dizer com relação ao bem-estar mental e social. O lado social é de fácil identificação, em função do estigma que recairia sobre as meninas em caso de retorno à tribo na situação em que se encontram, estando sua própria vida em risco. Restasse ainda alguma dúvida, esta seria eliminada pela declaração da mãe de Iganani, Muwaji, transcrita na matéria citada:

Se eu levá-la para a casa dos Zuruahã e ela não andar, vou ter que dar veneno pra ela. O meu coração não está nem pensando em voltar para os Zuruahã por causa da minha filha. Eu ficaria muito tempo com os brancos para ela melhorar.

Mais do que isso, o próprio bem-estar mental das crianças estaria irremediavelmente afetado. Na condição de homens brancos europeizados, é impossível 
para qualquer ocidental entrar na mente de um Zuruahã e ponderar o valor que atribuem à vida, inclusive à sua própria, que é extremamente pequeno. Este fato, além de ficar evidente na declaração do pai de Sumawani, Naru, ${ }^{25}$ foi objeto de estudos técnicos específicos, tendo sido constatado um alto índice de suicídios entre os Zuruahã desde seus tempos de isolamento, atingindo cerca de um terço do número de óbitos na tribo. ${ }^{26}$ Assim, fica claro que, no pensamento das pequenas índias depois de crescidas, muito provavelmente elas se considerariam vivendo uma vida que não deveria existir, o que lhes causaria profundo sofrimento moral e as levaria ao suicídio.

Por fim, o conceito sistêmico de saúde, tal como plasmado no art. 196 da $\mathrm{CF}$, enseja tratamento semelhante ao que é dado sobre o prisma do conceito da OMS. A diferença, particularmente nesse caso, reside apenas na terminologia. Aplicam-se as mesmas considerações empreendidas com relação ao bem-estar físico à noção de "redução do risco de doenças" e, de outra banda, cabe ao conceito de "outros agravos" o que se disse sobre o bem-estar mental e social.

A segunda questão a que nos propusemos responder respeita à aplicação da noção de saúde pública ao caso em tela. E, novamente, a resposta à pergunta exige uma retomada das diversas acepções atribuídas ao termo "saúde pública".

Entendida a saúde pública do modo tradicional, surgido na Inglaterra e perpetuado no modelo do Plano Beveridge até os modernos questionamentos, é impossível questionar o enquadramento da atitude dos missionários como medida de saúde pública. Não há dúvida de que a saúde pública, tal como entendida por Sueli Dallari no excerto transcrito acima, abrange uma face individual de colocar à disposição dos indivíduos os meios de recuperação de saúde, lembrando sempre que essa visão da saúde pública está atrelada a um conceito negativo de saúde. Inclusive, o caráter autoritário da atuação guarda toda consonância com o ideário que informava a saúde pública desde o seu surgimento.

Na seara da saúde coletiva, entretanto, não se pode repetir a afirmação. As críticas à saúde pública que culminaram na construção desse conceito guardam pertinência com as novas ideias acerca da saúde, notadamente de seu caráter processual e sistêmico. Assim, e pelas mesmas razões já expostas alguns parágrafos acima, não se pode considerar a ação dos missionários uma medida de saúde coletiva, na medida em que este conceito reinsere na problemática da saúde pública a discussão sobre o conceito de saúde. O grande mérito da noção de saúde coletiva talvez seja retirar a autonomia que havia sido emprestada à saúde pública, tornando-a um padrão universal da saúde, o que,

\footnotetext{
25 "Se o médico não operar, eu vou ter que dar veneno para ela, ela vai morrer. Eu também acabaria tomando veneno, eu ia me matar. Não temos medo de se matar”. A declaração também se encontra transcrita na mesma matéria.

26 Cf., a respeito, ERTHAL, Regina Maria de Carvalho. O suicídio Ticuna na região do Alto Solimões - AM. Tese (Doutorado) - Fundação Oswaldo Cruz, Escola Nacional de Saúde Pública, São Paulo, 1998.
} 
inevitavelmente, problematiza o universal a partir de seu embasamento em um aspecto particular já por si problemático.

Conclui-se, do exame deste caso, que a aplicação das modernas ideias acerca da saúde e da saúde pública leva à conclusão de que a saúde das meninas da tribo, considerada como um todo, é mais adequadamente promovida por meio de sua autorregulação, sem qualquer interferência europeizante.

\subsubsection{As testemunhas de Jeová}

As Testemunhas de Jeová são os integrantes de uma religião cristã que hoje se encontra espalhada por todo o mundo. Seus membros tornaram-se notórios por procederem a persistente evangelização de forma domiciliar, e por envolverem-se em polêmicas a respeito de tratamentos cirúrgicos, notadamente as transfusões de sangue. Com base em interpretações próprias a respeito de certas passagens da Bíblia Sagrada, ${ }^{27}$ as Testemunhas de Jeová recusam-se peremptoriamente a receber transfusão de sangue e tratamentos similares que envolvam sangue humano, incluindo o seu próprio (transfusão homóloga). ${ }^{28}$

A situação é perfeitamente análoga à das pequenas índias descrita acima, sendo inconveniente a repetição exaustiva de todos os argumentos e a aplicação das acepções de saúde e saúde pública também a este caso.

Sua menção, entretanto, é importante, uma vez que, dada a enorme repercussão social que este problema conheceu, e a luta aguerrida de diversos membros da religião para receberem tratamento médico segundo suas crenças religiosas, o sistema jurídico passou a aceitar a recusa das Testemunhas de Jeová ao recebimento de determinados tratamentos, inclusive excluindo a responsabilidade do médico nesses casos. Mais do que isso, a recorrência de situações idênticas levou a comunidade médica ao desenvolvimento de tratamentos alternativos, que vêm conhecendo bastante sucesso e já são aplicados em larga escala com baixos níveis de risco. ${ }^{29}$

O caso das Testemunhas de Jeová é emblemático porque nos mostra que não é necessário que se adentre em culturas alienígenas absolutamente diversas da cultura ocidental para que crenças religiosas e caracteres culturais entrem em choque com direitos fundamentais, até mesmo com os mais básicos, como o direito à saúde. Perfeitamente

\footnotetext{
27 A mais citada é Atos dos Apóstolos 15, 19-21.

28 Para mais detalhes sobre a doutrina, cf. TESTEMUNHAS de Jeová. Respeito pela vida e pelo sangue. Disponível em: <http://www.watchtower.org/t/rq/article_12.htm>. Acesso em: 1 maio 2012.

29 Para mais detalhes sobre a evolução jurídica do problema, que nos é impertinente no momento, e o andamento das pesquisas médicas, cf. TESTEMUNHAS de Jeová. O desafio cirúrgico/ético. Disponível em: <http://www.watchtower.org/t/hb/article_06.htm>. Acesso em: 01 maio 2012.
} 
integrados à cultura branca europeia, as Testemunhas de Jeová recusam-se a receber um tratamento médico que, durante muitos anos, antes do avanço das pesquisas, era o único disponível para determinadas situações de doença.

O problema colocado é decorrência direta do fenômeno da universalização dos direitos humanos, tratado doutrinariamente de forma ligada à questão do caráter irrenunciável dos direitos fundamentais, e, portanto, nos leva à última parte do estudo.

\section{A universalização dos direitos fundamentais e seu caráter irrenunciável}

Um dos debates mais candentes em matéria de direitos fundamentais é o relativo ao âmbito de sua abrangência, isto é, se são universais ou relativos. O problema é tormentoso, à semelhança do problema da relatividade ou universalidade da ética, sem solução na filosofia após dezenas de séculos.

A universalidade dos direitos fundamentais é uma tendência que tem por marco principal a edição pela Organização das Nações Unidas - ONU, da Declaração Universal dos Direitos Humanos, em 1948, embora suas bases teóricas remontem ao jusnaturalismo racionalista do século XVII. A tese universalista baseia-se no entendimento segundo o qual, sendo os direitos "humanos", têm por sujeito toda a humanidade e, consequentemente, incidem sobre ela no que possui de comum, tendo por fundamento uma razão natural inescapável.

O oposto lógico da universalidade é a relatividade. Com base no caráter eminentemente ético dos direitos humanos, a corrente doutrinária contrária sustenta a relatividade dos direitos humanos, que devem ter por limites o conteúdo religioso e cultural das diversas comunidades e sociedades em que são conquistados.

Consectário do caráter universal dos direitos humanos é seu caráter irrenunciável. A questão é causal. Se um direito fundamental é universal, incidindo sobre toda a humanidade de forma equânime, não é possível subtrair-se dele pela mera manifestação da vontade.

O debate entre universalistas e relativistas, embora constante e acalorado, é bastante repetitivo. Concentra-se sobremaneira na questão da mutilação genital feminina em determinados países africanos. A discussão sobre esse caso prático é, com a devida licença, quase pueril. O exemplo não possui os caracteres necessários que permitem sua avaliação com base no universalismo e na irrenunciabilidade. Trata-se de uma imposição dos dirigentes religiosos a mulheres que não tem liberdade de expressão e oportunidade de defesa, de modo que, ainda que o padrão cultural seja de aceitação generalizada, não é possível afastar a ideia de violência e provocação de dor e sofrimento, os quais, evidentemente, não são autoaplicáveis. 
O melhor campo para realizar o debate entre universalidade e relatividade, e este é o motivo do presente estudo, talvez seja o direito à saúde. Assim como foi feito com a mutilação genital feminina, centenas de páginas poderiam ser escritas a respeito da universalidade (ou não) do direito à saúde. Dificilmente, entretanto, seria captada a essência do problema, a diferença capital entre o caso do direito à saúde e o caso da mutilação, que reside justamente no caráter altamente subjetivo do conceito de saúde, já descrito acima. E toda subjetividade, sabe-se, é relativa.

Assim, a universalidade de um direito fundamental ou sua relatividade não pode ser afirmada peremptoriamente de forma desvinculada de seu objeto. Como consequência, não é possível construir uma teoria que sustente que todos os direitos fundamentais são universais ou relativos. O direito será universal, ou relativo, conforme o grau de subjetividade do seu objeto.

Pode parecer confortável e simplista uma argumentação nesse sentido, esvaziando o debate e propondo uma solução supostamente consensual. Entretanto, a crítica apressada há de ceder a duas inegáveis qualidades do argumento que ora se coloca.

Em primeiro lugar, a investigação da natureza do direito caso a caso a partir de seu objeto destaca uma característica, essa sim comum a todos os direitos fundamentais, e que frequentemente é deixada de lado pela doutrina: a historicidade. $\mathrm{O}$ caráter histórico dos direitos está umbilicalmente ligado à sua origem, e revela que cada um deles nasce em um contexto, por conta de determinadas demandas de classes ou grupos sociais, e que, por isso mesmo, cada direito será diferente do outro. Portanto, nada mais lógico do que investigá-los casuisticamente.

Além disso, os direitos fundamentais constituem um dos campos do saber jurídico mais permeáveis à interdisciplinaridade, seja com as demais ciências sociais, seja com outros ramos científicos, como as ciências médicas, no nosso caso específico. Diante disso, parece que a análise de cada direito fundamental por meio de seu objeto permite que o tratamento a ele dispensado seja o mais técnico possível, já que realizado com base no saber especializado das disciplinas pertinentes.

Feitas essas digressões teóricas, cumpre aplicá-las ao direito à saúde. A CF determina que o direito à saúde siga o princípio da universalidade. O que essa disposição significa em abstrato? Nada. A universalidade do direito à saúde somente fará sentido com referência ao seu objeto, o conceito de saúde.

As modernas tendências do conceito de saúde indicam que ela é um processo sistêmico, informado pela ideia de risco, tendo por objetivo atingir a harmonia entre o indivíduo e sua própria realidade. Sendo tal harmonia um objetivo utópico e inatingível, durante o processo teremos sempre um nível razoável de harmonia, sendo isso o que pode ser definido positivamente como saúde. Nesse contexto, o direito à saúde será o direito de 
cada um a gozar de harmonia com sua própria realidade, sempre tendo em vista que isso não se restringe à ausência de doença em sentido clínico.

Feitas as explicações necessárias, a pergunta pode ser novamente proposta em outros termos: o que significa atrelar o direito à saúde, subjetivamente entendida, ao princípio da universalidade? Significa universalizar o acesso aos meios de obtenção da almejada harmonia com a própria realidade. E isso, a toda evidência, não guarda qualquer relação com imposição de meios ou tratamentos. Se a realidade do indivíduo é dominada por sua vida religiosa, ou tribal, nada mais harmônico do que não se submeter a meios que contrariem suas crenças. Cumpre ao Estado, como garantidor do direito à saúde, colocar à disposição de todos - universalmente, portanto - meios que possam ser adotados sem quebrar a aludida harmonia. Se não há harmonia possível com a cultura, o ato de forçar medidas não trará garantia maior ao direito à saúde do que deixar que a cultura solucione o problema.

\section{Conclusão}

Acreditamos ter cumprido o objetivo a que o trabalho se propôs. A análise exaustiva do direito à saúde, inclusive em sua relação com a saúde pública, propiciou subsídios concretos que permitiram desmistificar o caráter universal e irrenunciável dos direitos humanos sustentado abstratamente pela doutrina. Esperamos que nossa conclusão seja tão sólida quanto nos pareceu, e que tenhamos lançado uma pequena semente para pesquisas mais profundas e detalhadas sobre o tema, que possam demonstrar definitivamente que a historicidade dos direitos humanos e seu diálogo interdisciplinar impedem que seu âmbito de abrangência seja delimitado sem referência ao objeto de cada direito individualmente considerado.

São Paulo, 30 de abril de 2015.

\section{Referências}

ALMEIDA FILHO, Naomar de. O conceito de saúde e a vigilância sanitária. Brasília: ANVISA, 2000 .

. O conceito de saúde: ponto-cego da epidemiologia? Revista Brasileira de Epidemiologia, São Paulo, v. 3, n. 1, p. 4-20, abr./dez. 2000.

CORREIA, Marcus Orione Gonçalves. Os direitos sociais enquanto direitos fundamentais. In: _ _ CORREIA, Érica Paula Barcha (Coord.). Direito previdenciário e constituição: Homenagem a Wladimir Novaes Martinez. São Paulo: LTr, 2004. p. 25-43. 
DALLARI, Sueli Gandolfi. O direito à saúde. Revista de Saúde Pública, São Paulo, v. 22, n. 1, p. 57-63, 1988.

. Uma nova disciplina: o direito sanitário. Revista de Saúde Pública, São Paulo, v. 4, n. 22 , p. 327-334, 1988.

DENARDINI, Cleiva. Conceito de saúde pública - saúde e enfermidade. Planejamento em saúde pública em relação ao direito à saúde. Revista da Saúde, Bagé, v. 5, n. 1, p. 52-62, 2000.

ERTHAL, Regina Maria de Carvalho. O suicídio Ticuna na região do Alto Solimões - AM. Tese (Doutorado) - Escola Nacional de Saúde Pública, Fundação Oswaldo Cruz, São Paulo, 1998.

FOUCAULT, Michel. O Nascimento da Medicina Social. In: . Microfísica do poder. Rio de Janeiro: Graal, 1999. p. 79-98.

REDE GLOBO DE TELEVISÃO. O drama de duas indiazinhas Zuruahã. Disponível em: < http:// fantastico.globo.com/Jornalismo/FANT/0,,MUL695084-15605,00.html>. Acesso em: 01 maio 2012 .

ROCHA, Júlio César de Sá. Direito da saúde: direito sanitário na perspectiva dos interesses difusos e coletivos. São Paulo: LTr, 1999.

SARLET, Ingo Wolfgang. A eficácia dos direitos fundamentais. 2. ed. Porto Alegre: Livraria do Advogado, 2001.

SCHWARTZ, Germano. Direito à saúde: abordagem sistêmica, risco e democracia. Revista de Direito Sanitário, São Paulo, v. 2, n. 1, p. 27-38, 2001.

SEGRE, Marco; FERRAZ, Flávio Carvalho. O conceito de saúde. Revista de Saúde Pública, São Paulo, v. 31, n. 5, p. 538-542, 1997.

TESTEMUNHAS de Jeová. O desafio cirúrgico/ético. Disponível em: < http://www.watchtower. org/t/hb/article_06.htm>. Acesso em: 01 maio 2012.

TESTEMUNHAS de Jeová. Respeito pela vida e pelo sangue. Disponível em: $<\mathrm{http}: / /$ www. watchtower.org/t/rq/article_12.htm>. Acesso em: 01 maio 2012.

WORLD HEALTH ORGANIZATION. Advanced health technologies and medical ethics: A WHO perspective. Disponível em: <http://www.who.int/ethics/en/S_Groth_Advanced_Health_ Technologies.pdf $>$. Acesso em: 01 maio 2012. 
